\title{
A contribuição da Arqueologia Clássica para os estudos sobre a infância na sociedade romana
}

\author{
The contribution of the Classical Archaeology to the studies on \\ childhood in the Roman society
}

CARROLL, M. Infancy and earliest childhood in the Roman World: a fragment of time. Oxford University Press: Oxford, 2018. 336 p.

\section{Jéssica Honório de Oliveira Silva*}

Recebido em: 15/12/2020 Aprovado em: 10/01/2021

N o livro Infancy and Earliest childhood in the Roman World, Maureen Carroll, arqueóloga e professora de Arqueologia Romana da Universidade de Scheffield, Reino Unido, busca investigar a morte, o luto e o contexto mortuário infantil a partir dos vestígios materiais. No capítulo primeiro, Introduction, a pesquisadora apresenta seu tema, seus recortes, suas motivações, seus objetivos e como foi organizado o livro. Sua preocupação foi, sobretudo, entender como os antigos romanos reagiam diante da morte de suas crianças e quais práticas ganhavam lugar naquele contexto.

Para Carroll, entendeu-se, durante muito tempo, em razão das expressões das fontes literárias, que os romanos não se importavam com suas crianças, não choravam em seus funerais e mantinham-se indiferentes frente aos assuntos sobre a infância. $O$ fato de as fontes escritas não terem privilegiado a criança como um de seus temas não revela, porém, o posicionamento dos romanos de todas as classes sociais do Império em todas as épocas e lugares.

O recorte temporal da investigação é amplo: parte do século IV a.C. e chega ao século IV d.C. Outra delineação abrangente é a espacial: a autora escolheu analisar todas as regiões do Império Romano que apresentassem evidências arqueológicas sobre a infância.

* Doutoranda pelo Programa de Pós-Graduação em História da Universidade Federal de Goiás sob orientação da Profa. Dra. Luciane Munhoz de Omena e bolsista da Coordenação de Aperfeiçoamento de Pessoal de Nível Superior (CAPES). 
A autora demonstra muita sensibilidade ao propor-se a pesquisar tal tema. Isso se manifesta em seus relatos sobre a experiência de acompanhar famílias que haviam perdido suas crianças em algumas reuniões e ir ao hospital visitar recém-nascidos em diversas condições. $\mathrm{O}$ empirismo somado à compreensão de que se tratava de um objeto delicado da existência humana revela, sem dúvida, a excepcionalidade do trabalho.

O segundo capítulo, Infants and children in Pre-Roman Mediterranean societies, foca na morte infantil e no sepultamento (locais, métodos de disposição do corpo e objetos dos túmulos), na gravidez e no nascimento retratados na arte pré-romana, em imagens da criança e da família na vida e na morte e nas imagens do divino no mundo grego. Neste capítulo, a arqueóloga questiona o lugar de enterramento das crianças nas sociedades pré-romanas, se elas eram enterradas em necrópoles comunitárias ou específicas. Não há, no entanto, uma única resposta. Existiram dois grandes grupos, situados em regiões das Europas Ocidental, Oriental e Central, que reagiram de maneiras distintas a respeito do enterramento dos bebês entre os séculos VIII a.C. e II a.C. O primeiro grupo sepultou seus bebês em edifícios funerários distintos daqueles da comunidade, enquanto o segundo grupo os enterrou nos cemitérios que incluíam também pessoas de outras idades.

Outro tipo de sepultamento acontecia em algumas colônias gregas, qual seja: o costume de sepultar bebês em potes, chamado de enchytrismos, que vigorou entre os séculos VIII a.C. e VII a.C. Um exemplo desse tipo de sepultamento provém de Erétria, na Eubeia, mas a prática foi verificada também em outras regiões do Mediterrâneo colonizadas pelos gregos, como no sul da Península Itálica, em Agrigento, na Sicília.

Entre os objetos encontrados nos túmulos, contam-se colares e anéis com pérolas de âmbar, de coral vermelho e dentes de animais, como o porco e o cervo. Esses artefatos eram usados para informar o gênero do bebê que perdeu a vida, como braceletes para indicar o sexo feminino e bolas para o masculino. Havia ainda objetos do "kit de casamento", como baús, cestos de lã, botas, roupas femininas, perfumes e bonecas. Assim, os objetos informam não somente sobre o morto, como também sobre os costumes, práticas, classes sociais e expectativas em relação à vida humana nas sociedades pré-romanas.

No capítulo terceiro, intitulado Mother and child: pregnancy, birth and health, a pesquisadora mostra os resultados de sua investigação sobre a saúde, o corpo e a morte da criança e da mãe. O desenvolvimento do bebê no útero, o nascimento e a morte no parto, os marcos importantes no primeiro ano de vida, a saúde, as doenças e a proteção divina delas são temas abordados neste capítulo. Carroll explica os perigos da gravidez para a mulher, naquela época, e as doenças que atingiam as mães. Para os antigos, era necessária grande atenção ao comportamento materno a fim de garantir 
uma boa e saudável gestação. À mulher eram imputadas proibições e responsabilidades pela gravidez.

Carroll narra ainda algumas práticas surpreendentes, como, em caso de haver um bebê morto no corpo da gestante, o ato de virar a mãe de cabeça para baixo para retirar o bebê, quebrar o crânio ou dissecar o corpo dele. O aborto, por sua vez, não era ilegal, porém havia uma condenação moral da mulher que o praticava, na medida em que estaria privando a cidade de ter um cidadão e o pai de ter um herdeiro que perpetuasse seu nome.

A criança sobrevivente ao parto tinha sua vida marcada por alguns acontecimentos que comemoravam sua sobrevivência ao longo do tempo. O primeiro marco era o die lustricus, o dia de receber o nome, que afirmava o pertencimento do bebê à família e à comunidade, conferindo-Ihe uma identidade social. Havia dois tipos de registros: a professio, destinada a crianças nascidas livres e aos filhos dos cidadãos romanos, e o testatio, o registro de crianças consideradas ilegítimas, que deveria ser feito com maior discrição.

O quarto capítulo do livro, The material culture of infancy, trata dos objetos encontrados nos túmulos das crianças, como mamadeiras, roupas, berços, cobertores, joias apotropaicas, animais e brinquedos. Nesse capítulo, o propósito da pesquisadora foi compreender o significado da inserção de tais objetos no contexto funerário.

Os objetos tinham caráter de proteção (em vida ou após a morte) e, para a sobrevivência do bebê, alguns deles imprimiam as expectativas dos pais quanto à longevidade do bebê ou da criança. Por exemplo, as faixas enroladas nos bebês tinham um significado moral: elas o preveniriam da moleza do corpo e da moleza moral, do espírito. Nas estátuas romanas, as crianças eram representadas cobertas com faixas e túnicas.

Colares e pulseiras eram objetos comumente usados pelas crianças. Pingentes, contas de vidro e de âmbar, pequenos falos em vidro e metal, ossos, sinos de bronze, moedas perfuradas, dentes de animais e de humanos e fragmentos de prata foram igualmente encontrados nas sepulturas. Quanto maior fosse a riqueza da qual a família da criança dispusesse, maior seria o número de objetos que compunha o colar.

Havia também a diferenciação de gênero. Uma pequena peça arredondada, o que a autora chama de spindle whorl, poderia referir-se ao futuro papel de mãe e dona de casa para as meninas, ao passo que, para os meninos, uma peça parecida, porém feita com chifre de veado, era símbolo de força, virilidade e renascimento. A autora é atenta ao observar as diferenças de gênero em sua pesquisa, informando ao seu leitor sobre o que cabia a cada um dos gêneros de acordo com os objetos depositados nos túmulos.

O quinto capítulo, Picturing infants and families in Roman Art, trata da representação imagética da criança. Em seus itens, a autora discorre sobre a consonância das imagens 
infantis com os interesses da permanência da família imperial no poder, pais e filhos de povos estrangeiros no Império, sarcófagos biográficos, retratos e estátuas de crianças.

Carroll inicia com a explicação da diferença que se estabeleceu, a partir do século I a.C., na imagética das crianças, que começaram a obter maior visibilidade no registro iconográfico, em especial aquelas que faziam parte da família imperial. Havia uma diferença nas representações conforme a faixa etária: crianças maiores eram, normalmente, representadas com seus pais, enquanto bebês de fralda eram representados com suas mães. As crianças não eram importantes apenas para compor as imagens imperiais em diversos veículos, mas, também, para consagrar as alianças políticas celebradas com os casamentos, garantir a transmissão da herança paterna e conservar as linhagens aristocráticas.

Outra fonte explorada por Carroll são os sarcófagos biográficos, que poderiam representar, por exemplo, a criança desde seu nascimento até a idade de sua morte acompanhada por seus pais. A autora estudou diversos sarcófagos de mármore do século II, que começam com o nascimento da criança, fazem alusão ao primeiro banho e prosseguem retratando todas as fases da vida do biografado até a sua morte. Retratos e estátuas de crianças também eram produzidos com frequência. Crianças mais velhas costumavam ser mais retratadas do que as crianças recém-nascidas devido ao apego maior que se tinha por crianças que viveram mais e tiveram mais tempo de convivência com seus pais.

Os sexto e sétimo capítulos possuem o mesmo título, Mors immatura, sendo divididos em duas partes, I e II. Os subtemas do capítulo sexto são mortalidade infantil, locais de sepultamento, sacrifício infantil, infanticídio e exposição. Ao discorrer sobre as estratégias dos pais para ter filhos e compensar a mortalidade infantil, a autora retoma sua tese de que os pais da Antiguidade se importavam com suas crianças e bebês. Para ela, o sepultamento de bebês que não nasceram com vida e tiveram de ser retirados do útero de suas mães são evidências da inclusão social dessas crianças e do envolvimento emocional dos pais.

Suggrundaria (locais de sepultamento de crianças que ainda não tinham vivido quarenta dias), necrópoles comunitárias ou específicas para crianças, lugares abandonados, quartos e fortes militares compunham o conjunto de lugares de sepultamento de crianças na Antiguidade.

Sobre o sacrifício de crianças, Carroll não defende a ideia de que o sacrifício humano fosse uma prática comum na sociedade romana. Outra prática que também não parece ter sido corriqueira é o infanticídio motivado pelo nascimento de crianças com algum tipo de deficiência. Segundo a autora, a exposição também não o era, mas acontecia devido às péssimas condições sociais das famílias pobres e ao nascimento de 
crianças com deficiência. A arqueóloga mostra-se cuidadosa ao não afirmar a existência de práticas sem evidências.

O sétimo capítulo, Mors immatura II, discorre sobre o corpo infantil na morte: a forma de tratamento do corpo, o local de acomodação e os objetos que o acompanhavam. A autora inicia o capítulo exemplificando as práticas de enterramento em um local específico, Marselha. Essa cidade, no sul da atual França, oferece múltiplas possibilidades para o arqueólogo que busca vestígios da morte: ela comporta o passado grego e romano, já que foi colônia das duas civilizações. Sob duas diferentes perspectivas culturais, Marselha conta com práticas distintas diante da morte e do corpo infantil. Os gregos sepultavam seus bebês e crianças em necrópoles coletivas. No período grego, era comum sepultar bebês em ânforas. Já no romano, essa prática era muito pouco utilizada, pois os romanos sepultavam suas crianças em caixões.

Deixando o espaço de Marselha e expandindo o campo geográfico da pesquisa, a autora discorre sobre a cremação e a inumação. Segundo os vestígios arqueológicos, poucas crianças eram cremadas. A tese de Carroll é a de que não havia, no entanto, uma uniformidade de sepultamentos, uma vez que existia uma variedade de práticas que não podem ser padronizadas. A mumificação, por exemplo, era uma prática comum no Egito romano não apenas para adultos e crianças, como também para fetos e bebês. Não há nem mesmo como determinar quais práticas eram exclusivas para enterramentos de adultos.

Além dos objetos já mencionados no quarto capítulo, artefatos como moedas, depositadas na boca ou na mão, estão ligados à passagem da vida à morte e até mesmo à negociação após a morte. Lâmpadas com óleo também não eram objetos incomuns. Em um cemitério, situado no Vaticano, foi encontrada uma criança enterrada com um ovo de galinha, o que exemplifica enterramentos com comida. Na Gália romana, a terra sigillata (prato de cerâmica) também costumava ser depositado junto às crianças, nas sepulturas.

O oitavo capítulo, Funerary commemoration of infants, é dedicado às inscrições e aos retratos nas lápides e nos monumentos funerários. Assim como em todos os capítulos anteriores, este também é permeado pela defesa da relevância das crianças para as famílias. Dedicar uma inscrição para um bebê de menos de um ano de idade ou para um adulto de quarenta anos era algo muito especial.

Nas inscrições dedicadas às crianças, eram especificados seu tempo de vida, seu nome e quem lhes ofereceu aquela inscrição - comumente os pais. Qualidades morais, no superlativo, também eram escritos: carissimus, dulcissimus, suavissimus e pientissimus. 0 substantivo adjetivado mater infelicissima também aparecia para qualificar a dor da mãe ao perder seu filho ou filha. Outra forma de rememoração eram os retratos. Muitas vezes 
as crianças eram retratadas com outra aparência, distinta daquela que tinham em vida, além de serem identificadas com deuses e deusas.

O nono capítulo, Integrated perspectives on Roman infancy, é conclusivo. Nele, Carroll comprova que os vestígios encontrados contrariam a ideia de comedimento do luto. O objetivo do capítulo é avaliar alguns textos de autores romanos que influenciaram o julgamento que se teve a respeito da relação entre pais e filhos, como Consolação para a esposa, de Plutarco.

O impedimento do luto formal, no caso de morte de crianças de menos de três anos, e a inexistência de rituais na morte de crianças são ideias refutadas pela cultura material. Os sexto e sétimo capítulos discorreram sobre a preparação do corpo da criança, o lugar do enterramento e os objetos e rituais dedicados a ela. A balsamaria (ato de perfumar o corpo do morto), na Gália romana, e a libação (derramamento de líquido em oferecimento aos deuses) faziam parte dos rituais funerários.

Todas as práticas de cuidado com o corpo, de sepultamento, de oferendas aos deuses em rituais, de se presentear com objetos e de inserção de relevos no túmulo são performances sociais da morte que contrariam o sentido das leis romanas. Sem essa compreensão, a pesquisa de Carroll não teria razão de ser executada. O sucesso da autora está em desconfiar das fontes escritas, porém, ao mesmo tempo, admiti-las como informantes de outra prática acerca da morte: aquela da moderação estoica da dor nos círculos das elites romanas.

Para a autora, a discrepância entre a lei e a realidade explica-se na manifestação das emoções, que desobedeciam a regulações e medidas. A dor dos familiares ao perder um filho não encontrava consolo no silêncio e sim em práticas que pudessem construir a memória da criança.

Se as leis a respeito do sepultamento e do luto intentavam controlar as elites romanas, as práticas sociais da morte eram realizadas por todas as classes sociais. As prescrições legais, no entanto, não proibiram os familiares de chorar e de dedicar atenção à morte de seus filhos. O luto era vivido como podia sê-lo, de acordo com cada realidade.

Maureen Carroll fez uma pesquisa de fôlego a fim de comprovar sua tese. No campo das fontes, explorou vestígios materiais, revelando suas composições, seus significados e usos. No campo das práticas, apresentou o significado de cada uma delas e suas variações geográficas e teve muito cuidado em não as generalizar no tempo e no espaço. Aprendese, com Carroll, que os antigos enfrentaram a morte de muitas maneiras. No campo dos conhecimentos auxiliares da Arqueologia, a pesquisadora demonstrou total aptidão ao lidar com a Bioarqueologia, tendo o cuidado de esclarecer termos complexos a respeito do corpo humano. 
Em suma, Infancy and earliest childhood in the Roman World é uma obra indispensável para os especialistas em estudos sobre a infância e a morte na sociedade romana. Para os arqueólogos, ela representa um estudo essencial em termos de método de pesquisa arqueológico, de busca de materiais e de sua interpretação. O livro nos ensina a pesquisare não a ocultar os limites ao se interpretar os vestígios encontrados. Para o público brasileiro, a pesquisa de Carroll é de uma riqueza documental difícil de ser alcançada em nosso país. Por fim, a autora oferece aos arqueólogos e historiadores uma nova perspectiva acerca da criança e da morte, ao eleger a criança como um ser importante socialmente e sua morte como um objeto de estudo que abre caminho para a compreensão de diversos aspectos das sociedades antigas. Assim, Carroll oferece um lugar privilegiado de pesquisa sobre aqueles que já se foram e demonstra que o enfrentamento da morte foi, na Antiguidade, um acontecimento plural.

\section{Referência}

PLUTARCH. Moralia. Translated by Phillip H. De Lacy and Benedict Einarson. Cambridge: Harvard University Press, 1959. v. 7. 